\title{
Concomitant Occurrence of Vestibular Schwannoma and Epidermoid Cyst in Neurofibromatosis: Case description and Review of the Literature
}

\section{Ocorrência concomitante de schwannoma vestibular e cisto epidermoide em neurofibromatose: descrição de caso e revisão da literatura}

\author{
Alex Roman ${ }^{1,2}$ Edson Najera ${ }^{2}$ Toma Spiriev ${ }^{2}$ Kristoph Ramina ${ }^{2}$ Luigi Rigante ${ }^{2}$ \\ Marcos Soares Tatagiba ${ }^{2}$ \\ ${ }^{1}$ Hospital São Vicente de Paulo, Passo Fundo, RS, Brazil \\ 2 Universitätsklinikum Tübingen, Tübingen, Germany \\ Address for correspondence Alex Roman, MD, Hospital São Vicente \\ de Paulo, Rua Uruguai 1737, 601, Passo Fundo, RS, Brazil \\ (e-mail: alexroman__@hotmail.com).
}

Arq Bras Neurocir 2017;36:230-233.

\begin{abstract}
We report a case of a 16-year-old female patient harboring neurofibromatosis type 2 who presented with bilateral hearing impairment, which was on the left side, as well as facial paresis (House-Brackmann grade III) and ataxic gait. A magnetic resonance imaging (MRI) exam evidenced bilateral lesions in the cerebellopontine angles (CPAs) with extension into the internal acoustic meatus, and an additional lesion in the right CPA with radiological characteristics of an epidermoid cyst. The patient was submitted

\section{Keywords}

- vestibular schwannoma

- epidermoid cyst

- multiple intracranial lesions

\section{Resumo}

\section{Palavras-chave}

- schwannoma vestibular

- cisto epidermoide

- leões intracranianas múltiplas to microsurgical resection, confirming a collision of a vestibular schwannoma and an epidermoid cyst in the right CPA. In the present case report, we describe the first case reported in the literature with preoperative diagnostic work-up, intraoperative findings, postoperative course of the patient, as well as a detailed literature review of these specific coinciding pathologies, denoting the importance of further genomic studies regarding multiple central nervous system (CNS) lesions.

Relatamos o caso de uma paciente de 16 anos de idade com neurofibromatose tipo II com deficiência auditiva bilateral, pior no ouvido esquerdo, assim como paresia facial (HouseBrackmann grau III) e ataxia. Estudo de ressonância magnética comprovou lesão bilateral nos ângulos cerebelopontinos (ACPs) com extensão ao meato acústico interno, e uma lesão adicional no ACP direito com características radiológicas de um cisto epidermoide. A paciente foi submetida a ressecção microcirúrgica, confirmando a colisão de um schwannoma vestibular com um cisto epidermoide no ACP direito. No presente estudo, descrevemos o primeiro caso relatado na literatura com trabalho diagnóstico pré-operatório, resultados intraoperatórios, evolução da paciente no pós-operatório, assim como revisão detalhada da literatura específica sobre essas patologias, demonstrando a importância de mais estudos genômicos sobre as múltiplas lesões do sistema nervoso central (SNC).
\end{abstract}

received

February 25, 2017

accepted

August 16, 2017

published online

September 26, 2017
DOI https://doi.org/

$10.1055 / \mathrm{s}-0037-1606623$.

ISSN 0103-5355.
Copyright $\odot 2017$ by Thieme Revinter

Publicações Ltda, Rio de Janeiro, Brazil

License terms

c) $(1) \$$ 


\section{Introduction}

The occurrence of multiple brain tumors is extremely rare, and has been reported to be of $\sim 0.3 \%$, excluding those cases with diagnosed phacomatosis or those who have undergone previous radiotherapy. ${ }^{1,2}$ Although patients may develop different tumors along their lifetime, concomitant vestibular schwannoma and epidermoid cyst in a single patient is a rather uncommon presentation. It has been previously demonstrated that vestibular schwannomas seem to carry diverse genetic anomalies, specifically in cases of neurofibromatosis, with the patients usually presenting symptoms after the age of 30 , coursing most commonly with the known triad of sensorineural hearing loss, tinnitus and balance difficulties. ${ }^{3}$ However, it seems that epidermoid cysts arise during the intrauterine development, and they are believed to originate from epidermal inclusions during the formation of the second cerebral vesicle. The described incidence of vestibular schwannomas is of approximately $1.5 / 100.000$ people, accounting for $7-10 \%$ of all primary intracranial tumors. Earlier reports have stated that epidermoid cysts present an incidence of around 6\% of that of vestibular schwannoma, and that the occurrence of both of these tumors simultaneously in the cerebellopontine angles (CPAs) is rarely reported. ${ }^{3-5}$ In the present description, we present a rare case of simultaneous occurrence of these tumors in a neurofibromatosis type 2 (NF2) patient. The preoperative diagnostic work-up, intraoperative findings and subsequent management are presented in the current report, and a systematic literature review was also performed.

\section{Case Presentation}

We report a case of a 16-year-old female presenting with bilateral hearing impairment (which was worse on the left side), with relative rapid progression, with evolution to facial palsy (House-Brackmann grade III [HBIII]) on the right side. Upon clinical examination, an important decrease in hearing function on the right side was noticed, with complete nonfunctional hearing on the left side. The patient also presented a cervical subcutaneous tumefaction compatible with a local neurinoma. Upon the magnetic resonance imaging (MRI) exams, the presence of bilateral lesions on both CPAs in the topography of the vestibulocochlear nerve complex was observed, with concomitant enlargement of the internal acoustic canals (IACs). The lesions displayed an enhancement with gadolinium contrast, homogeneously on both CPAs, corresponding to the images characteristic of bilateral vestibular schwannomas. However, an additional image had been observed in the right CPA adjacent to the first enhancing lesion, with a heterogeneous feature and a cystic non-enhancing appearance, producing an important space-occupying lesion, which compressed the brainstem. Additionally, the rightsided non-enhancing lesion displayed isointense to hypointense characteristics on T1-weighted images (T1WIs), and a hyperintense signal on T2-weighted images (T2WIs). In the diffusion-weighted imaging (DWI) sequence, this lesion portrayed restriction of water movement with high signal image. These MRI findings raised preoperatively the suspicion of lesions compatible with bilateral vestibular schwannomas in the CPAs, as well as a dysembriogenic epidermoid cyst (-Fig. 1). Upon further radiological investigation, an additional lesion within the high cervical spinal cord was visualized, which was suggestive of an ependymoma. After thorough clinical and radiological investigations, the diagnosis of NF2 was made, as the patient had met the specific criteria.

We opted for elective microsurgical resection of the right vestibular schwannoma and adjacent cystic lesion, due to the pronounced brainstem compression and the progressive facial nerve paresis (HBIII), with preservation of serviceable hearing on this side, as in comparison to the non-serviceable

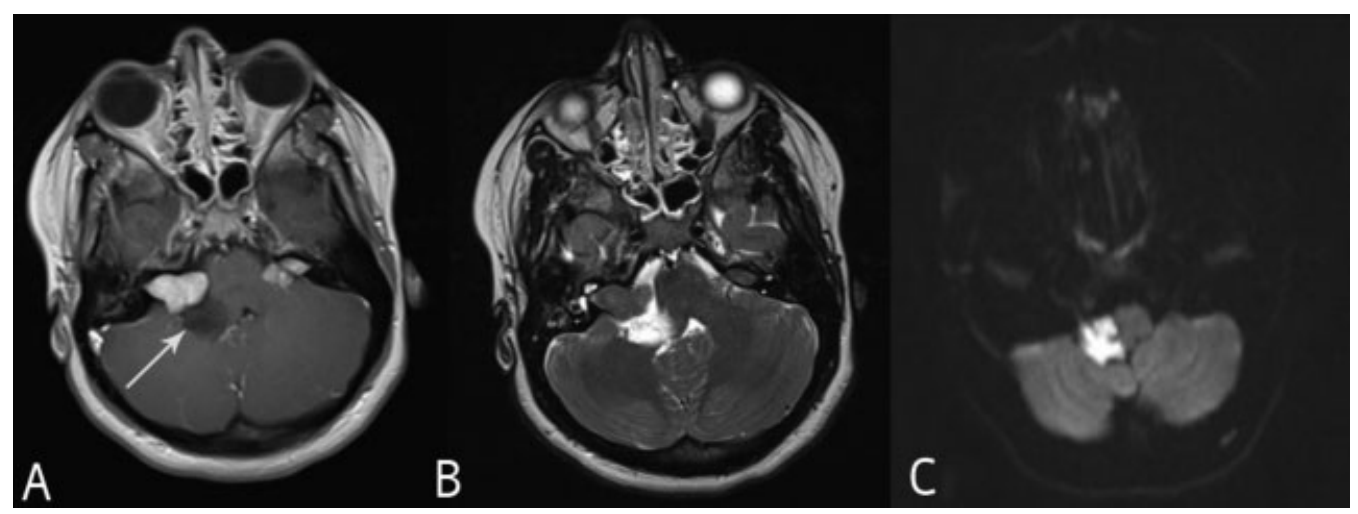

Fig. 1 (A) T1-weighted image (T1WI) demonstrating bilateral, hyperintense, contrast-enhancing lesions in the cerebellopontine angles (CPAs) with extension within the internal auditory canal (IAC), which are consistent with bilateral vestibular schwannomas. A hypointense lesion adjacent to the right CPA tumor (white arrow) is visible, which is compressing the brainstem. (B) T2-weighted image (T2WI) depicting a hypointense lesion consistent with vestibular schwannoma in the right CPA, adjacent to an additional hyperintense lesion with a cystic appearance, with signal intensity similar to that of the cerebrospinal fluid (CSF). (C) Diffusion-weighted imaging (DWI) showing an intense signal in the topography of the hyperintense T2WI lesion in the right CPA, with restriction of water movement, co-responding to the image characteristics of an epidermoid cyst. 
hearing on the left side. The procedure was performed through a right subocciptal retrosigmoid approach in the semi-sitting position, under neurophysiological monitoring of the motor-evoked potentials (MEPs), somatosensoryevoked potentials (SSEPs) and auditory-evoked potentials (AEPs).

After performing the subocciptal retrosigmoid craniotomy, the lateral cerebellomedullary cistern was dissected, enabling cerebrospinal fluid (CSF) drainage, to allow for posterior fossa relaxation and produce less need of cerebellar hemispheric retraction, creating a surgical corridor, after applying self-retaining brain retractors. Posterior to the right cerebellar hemispheric retraction, two distinct intraoperative findings could be observed: separate arachnoid cleavage planes (-Fig. 2 ). The caudal lesion had the poorly vascularized flaky and pearly appearance compatible with an epidermoid cyst. The more cranial lesion, on the other hand, had been located in the topography of the IAC, with clear classic characteristics of a VIII nerve schwannoma, which was enlarging and protruding outside the IAC, compressing the brainstem at the level of the pons. Using careful microsurgical dissection ( - Video $\mathbf{1}$ ), the epidermoid cyst was initially removed, paying special attention to the meticulous microdissection of the capsule of the tumor, which was tightly adherent to the caudal cranial nerve $(\mathrm{CN})$ complex (CNs IX, X and XI). After the cyst, its content and wall were removed, attention was devoted to the superiorly located vestibular schwannoma. The tumor was removed using a standard microsurgical technique, ${ }^{6}$ including opening the IAC, internal debulking, followed by extracapsular dissection and identification of the VII cranial nerve using intraoperative monitoring and stimulation. The vestibular schwannoma was subtotally removed due to a transitory decrease in the AEP during the resection (-Fig. 3). Both lesions were confirmed (by a frozen biopsy study and later lamina anatomopathological verification) as two histologically different lesions, a tumor consistent with a schwannoma (World Health Organization [WHO] Grade I) and an epidermoid cyst.

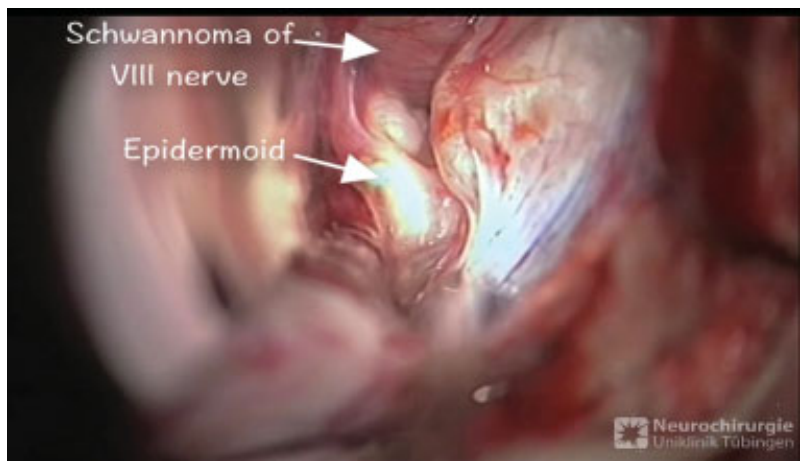

Fig. 2 Intraoperative photograph demonstrating two distinct lesions in the right CPA. The cranial lesion extends from within the internal acoustic meatus, which is consistent with a vestibular schwannoma. The caudal lesion has a pearl-white color, and it was flaky at dissection, which is consistent with an epidermoid cyst. Both lesions were confirmed by an anatomopathological study.

\section{Video 1}

Intraoperative video. Online content including video sequences viewable at: www.thieme-connect.com/ products/ejournals/html/10.1055/s-0037-1606623.

The postoperative course of the patient was uneventful, with no worsening of the preoperative facial nerve function and preserved serviceable hearing.

\section{Discussion}

The occurrence of multiple central nervous system (CNS) tumors in the course of neurofibromatosis is well knonw, ${ }^{4,7-9}$ although the presence of vestibular schwannoma concomitantly with epidermoid cyst in the neurofibromatosis syndrome has not been previously reported in the literature. A small number of reports have demonstrated the occurrence of epidermoid cysts in concomitance with vestibular schwannomas, with one report describing the occurrence of a vestibular schwannoma posterior to the resection of an epidermoid cyst, ${ }^{10}$ and other reports describing non-neurofibromatosis cases, ${ }^{4}$ making, to the best of our knowledge and after a systematic review of the current literature, this case report the first to document this specific circumstance.

In the case presented, the patient developed progressive symptoms of a CPA-occupying lesion, with hearing impairment, as well as facial palsy and an ataxic gait that could be attributed to a further lesion, an intramedullary tumor present in the high cervical spinal cord. The work-up evidenced two distinct lesions in the right CPA, as well as another lesion in the left CPA, which was consistent with a schwannoma, and an intramedullary lesion in the high cervical spinal cord. In the right $\mathrm{CP}$, there was evidence of a lesion in the topography of the internal acoustic meatus, hypointense to isointense on T1WI, enhancing with gadolinium contrast, and also slight hyperintense on T2WI, an image compatible with a vestibular schwannoma. The other lesion

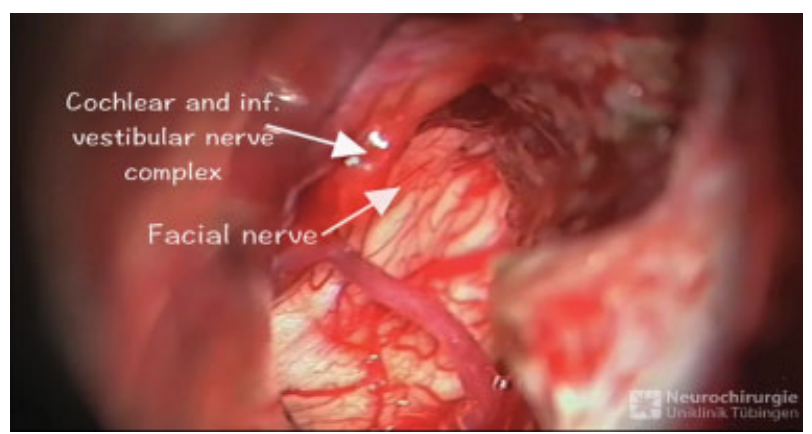

Fig. 3 Photograph of the surgical field after gross total resection of the lesion consistent with an epidermoid cyst, and after subtotal removal of the tumor in the vestibulo-cochlear complex, demonstrating the cochlear and inferior vestibular nerves, as well as the preservation of the facial nerve. 
showed a hypointense signal on T1WI, slightly more intense than the CSF and showing hyperintensity on T2WI, with an intense signal on DWI ( - Fig. 1 ), which raised the suspicion of an epidermoid cyst.

The surgical procedure was performed in a semi-sitting position, through a subocciptal retrosigmoid approach, with intraoperative monitoring with special attention given to facial nerve motor monitoring and AEP. Transoperatively, two diverse lesions could be observed. The first was a flaky, pearl-white lesion, poorly vascularized, for which gross total resection was performed. Afterwards, we treated the other lesion, which was located in the topography of the internal acoustic meatus, in close relation to the facial and vestibulocochlear complex, and that was partly adherent to the facial nerve (-Figs. 2, 3). Due to a transitory decrease in the AEP, we opted to perform a subtotal resection, due to patient's serviceable hearing in the side being operated, and a nonserviceable response on the other side, specifically respecting this preoperative clinical presentation during the decisionmaking process in the intraoperative course.

In a previous study, ${ }^{10}$ data suggest that the origin of certain vestibular schwannomas may arise from the irritative effect of the remnant epidermoid cyst or of previous surgical procedures. Histological examination is essential to rule out malignant cells, and to attempt to plan the postoperative management, without the need of adjuvant therapies. Cerebellopontine angle lesions may vary in histological findings, and range from meningiomas, vestibular schwannomas, epidermoid cysts and other benign tumors to malignant lesions. Even though malignant lesions are not common in the region, they may arise within the boundaries of the CPA, including chordomas, chondrosarcomas, carcinomas and other metastatic lesions that may arise intracranially, supratentorially, as well as infratentorially, including those of the CPA, and they must also be ruled out before planning the management. Less commonly, lipomas, arachnoid cysts and other miscellaneous lesions may be present in the region, but current imagining technologies may render information to preoperatively provide tips as to the nature of the studied lesion. The predisposition to harbor an epidermoid cyst in NF2 patients, with partial deletion of chromosome 22q12 or total deletion of chromosome 22, is not well stablished, and the concurrence of such tumors may be incidental findings. The origin of the latter may be not related to NF2, but further studies could bring forth evidence otherwise.

Atypical lesions that have different aspects upon initial imagining exams should undoubtedly be further investigated, as the initial computed tomography scan may offer little information, especially in the posterior fossa, as the petrous bony structures may alter the findings and produce confounding information. On the other hand, the MRI generally produces much richer evidence, and the diagnosis is facilitated when distinct imagining techniques are employed, including contrast enhancement, fat suppression and DWI, which may produce a rather specific hyper intense image, ${ }^{11}$ reducing the confounding factors for such lesions.

The consideration of distinct diagnoses, aside from the initial suspicion of the typical clinical and imaging features of vestibular schwannomas, should include other less common tumors that may also be part of the large spectrum of differential diagnosis, and must therefore be considered as possible CPA lesions before planning the specific management.

\section{Conflicts of Interest}

The authors state that there are no conflicts of interest regarding the present article.

\section{References}

1 Gardner WJ, Turner OA. Multiple Intracranial Tumors: A discussion of the relation of meningeal to acoustic tumors and a report of a case. JAMA 1939;113:111-113

2 Kuroiwa T, Ohta T, Kobata H, Yamamoto H, Kimura N. Coexistence of intracranial meningioma and primary malignant lymphomacase report. Neurol Med Chir (Tokyo) 1990;30(04):268-271

3 Goodman RR, Torres RA, McMurtry JG III. Acoustic schwannoma and epidermoid cyst occurring as a single cerebellopontine angle mass. Neurosurgery 1991;28(03):433-436

4 Kleinpeter G, Matula C, Koos W. Another case of acoustic schwannoma and epidermoid cyst occurring as a single cerebellopontine angle mass: possibly not so rare? Surg Neurol 1994; 41(04):310-312

5 Sastri BVS, Babu HVS. Concomitant Occurrence of Vestibular Schwannoma and Epidermoid Cyst. Indian J Neurosurg. 2013; 2(03):282-283

6 Tatagiba M, Roser F, Schuhmann MU, Ebner FH. Vestibular schwannoma surgery via the retrosigmoid transmeatal approach. Acta Neurochir (Wien) 2014;156(02):421-425, discussion 425

7 Lee KS, Seo EK. Two primary intracranial tumors of different histology: report of a case with a choroid plexus papilloma and a concurrent vestibular schwannoma in the cerebellopontine angle. Yonsei Med J 2002;43(01):133-137

8 Muzumdar DP, Goel A, Desai KI. Pontine glioma and cerebellopontine angle epidermoid tumour occurring as collision tumours. Br J Neurosurg 2001;15(01):68-71

9 Talacchi A, Giorgiutti F, Andrioli M, Turazzi S, Bricolo A. Intracranial coexistence of neurinoma with epidermoid cyst or cholesterol granuloma. Report of 2 cases. J Neurosurg Sci 1997;41(02): 179-188

10 Saito A, Sugawara T, Watanabe R, Akamatsu Y, Mikawa S, Seki H. Evolution of vestibular schwannoma after removal of epidermoid cyst of the same location: case report. Neurol Med Chir (Tokyo) 2009;49(10):495-498

11 Springborg JB, Poulsgaard L, Thomsen J. Nonvestibular schwannoma tumors in the cerebellopontine angle: a structured approach and management guidelines. Skull Base 2008;18(04): 217-227 